\title{
Desafios para objetivação da Pedagogia Histórico- Crítica na prática escolar
}

\author{
Carlos Henrique Ferreira Magalhães \\ Universidade Estadual de Maringá \\ João dos Reis Silva Júnior \\ Universidade Federal de São Carlos
}

\section{Resumo}

Este artigo visa analisar os desafios pedagógicos fundantes para a educação numa sociedade cindida em classes. Embora o Professor Saviani indique que a ausência de um sistema de educação, a necessidade de reorganização das escolas e as descontinuidades de políticas educacionais sejam os desafios para a educação brasileira, acreditamos que os desafios estão para além destas indicações. Essa percepção nos deixa em estado de alerta às possibilidades reais de continuidade de políticas educacionais que possam favorecer, predominantemente, os filhos da classe trabalhadora, haja vista que as soluções formais não são capazes de enfrentar a lógica destrutiva do capital. Entendemos que as políticas educacionais sejam soluções formais, e, embora elas possam preconizar pequenas mudanças e indicar alguma melhoria local, não são capazes de romper com a substância histórica em que o acúmulo do capital impõe o acúmulo de miséria.

Palavras-chave: Pedagogia Histórico-Crítica. Prática escolar. Ontologia marxiana. 


\section{Challenges for actualizing the Historical Critical Pedagogy in school practice}

This article aims at analyzing the foundational pedagogical challenges for education in a society divided into classes. Although professor Saviani indicates that the absence of a system of education, the need to reorganize schools, and the discontinuities of educational policies are the challenges of Brazilian education, we believe that the challenges reach beyond these indications. This perception makes us alert to the real possibilities of continuing educational policies that are capable of favoring, predominantly, the children of the working class, since formal solutions are not capable of facing the destructive logic of capital. We understand that educational policies are formal solutions, and although they may profess small changes and indicate some local improvement, they are not capable of breaching the substantive history in which the accumulation of capital imposes the accumulation of misery.

Keywords: Historical Critical Pedagogy. School practice. Marxian ontology.

\section{Desafíos a la objetivación de la Pedagogía Histórico- Crítico en la práctica escolar}

Este artículo tiene como objetivo analizar los desafíos pedagógicos que fundamentan la educación en una sociedad dividida en clases sociales. A pesar que el profesor Saviani crea que la ausencia de un sistema de educación, la necesidad de reorganización de las escuelas y las discontinuidades de políticas aducativas sean los desafios para la educación brasileña, creemos que los desafios van más allá de estas indicaciones. Este hecho conlleva un estado de alerta con las posibilidades reales de continuidad de políticas educativas que puedan favorecer predominantemente los hijos de la clase trabajadora, en vista de que las soluciones formales no son capaces de enfrentar la lógica destructiva del capital. Entendemos que las políticas educativas son soluciones formales. Aunque ellas puedan preconizar pequeños cambios e indicar una cierta mejora local, no son capaces de romper con el hecho histórico que la acumulación de capital impone un aumento de la miseria.

Palabras clave: Pedagogia Histórico-Crítica. Práctica escolar. Ontología marxiana. 


\section{Introdução}

No momento em que nos propusemos analisar os desafios para a objetivação da Pedagogia Histórico-Crítica, como sugerida pelo professor Saviani (2008, 2007,1994, 2003), o Departamento de Psicologia da Educação da Unesp de Araraquara realizava o Simpósio Pedagogia Histórico-Crítica: 30 anos, entre os dias 15 e 17 de dezembro de 2009.

Acreditamos que seja louvável a iniciativa de discutir, estudar, refletir a respeito da Pedagogia Histórico-Crítica com o seu precursor que foi, e ainda é, um professor de suma importância para a educação brasileira. Todavia, para aqueles que buscam uma educação contra o capital ou uma educação para além do capital, conforme sugerem os professores Ivo Tonet e István Mészáros, percebem-se fatos que nos exigem rever alguns pressupostos defendidos pelo Professor Demerval Saviani, haja vista suas posições conflitantes.

Destacamos como inegável a defesa da escola pública, gratuita e de qualidade que o professor Demerval Saviani tem feito ao longo de sua vida. Contudo, deparamo-nos com críticas à sua concepção de Estado, bem como à apropriação de Antonio Gramsci realizada no Brasil, a qual depurou sua condição de defensor do Comunismo. Também refletimos sobre os pressupostos apontados por Demerval Saviani aos desafios da Pedagogia Histórico-Crítica com amparo das obras de Ivo Tonet e István Mészáros. Neste sentido, pretendemos contribuir com o debate, lembrando que isso não significa desmerecer nem desqualificar as reflexões do autor que agora será analisado.

\section{Os desencontros da Pedagogia Histórico-Crítica com os aspectos fundantes da atual sociabilidade}

O estudo a respeito da Pedagogia Histórico-Crítica nos proporcionou o levantamento de fatos e ideias de que não desconfiávamos. Dentre eles, as críticas feitas aos autores críticos na educação. Já conhecíamos as análises de Ivo Tonet (2005a) aos autores que ele denominou como a esquerda democrática na educação. Ali, Tonet debateu com Frigotto, Nosella, Freire, Gadotti, Arroyo e Libâneo. Por meio de uma análise ontológica, indicou ser uma "[...] brutal ilusão querer colocar a educação a serviço da formação de cidadãos, especialmente nos países pobres" (Tonet, 2005a, p. 123). Tonet quer nos dizer que, quando esses autores têm no seu horizonte a cidadania, perdem a crítica radical da emancipação humana, ao priorizarem somente a emancipação política. A emancipação humana exigiria a supressão das classes, do Estado, do capital e do trabalho alienado/estranhado. 
Este viés talvez tenha sido corroborado em virtude de uma virada no movimento socialista mundial, a partir da década de 1940, com a proposição do socialismo democrático. A tentativa dos partidos comunistas europeus de negar as atrocidades de Stalin, ao invés de resgatar os pressupostos da concepção marxiana promoveu a fragilização dos pressupostos marxianos que visam à superação do trabalho alienado, do estado e do capital. Dessa forma, o socialismo democrático, como pressuposto dos autores citados no campo da educação, tornou-se refém da ideia de formar cidadãos críticos. 0 que, para Tonet $(2007,2005 a, 2005 b)$, não nos permite conquistar a emancipação humana.

Contudo, ainda não tínhamos nos deparado com críticas àquele que formou Frigotto, Nosella, Libâneo, entre outros autores do campo da educação, o professor Demerval Saviani. Em outubro de 2007, conhecemos a obra de Sergio Lessa (2007), na qual ele faz análises de diversos autores que se apropriaram da categoria trabalho e nela se apoiaram para as suas teorizações. Lessa examina de forma crítica e rigorosa como a categoria trabalho fora apropriada por Demerval Saviani. Lessa destaca, de início, ser inquestionável o fato de Saviani ser um defensor do socialismo no campo da educação. Todavia, quando indica o trabalho educativo como pressuposto da Pedagogia HistóricoCrítica, faz uma crítica a essa concepção. Considerando que o trabalho é a intervenção do ser humano na natureza, Lessa questiona a possibilidade de o trabalho ser princípio educativo.

Em sua análise, Lessa (2007) evidencia que Saviani entende o trabalho como uma intervenção do indivíduo na natureza, assim como Karl Marx e Georges Lukács também o interpretam. Contudo, Lessa, logo a seguir, indica que Saviani observa que tanto no trabalho como na educação o ser humano aponta finalidades. Com isso, identifica educação e trabalho e aponta este como princípio educativo para a educação. Todavia, Lessa, com aporte em Lukács, lembra-nos que há teleologias primárias do aspecto fundante do ser social, o trabalho, e teleologias secundárias, de outros complexos fundados pelo trabalho e com autonomia, como a arte, o direito, a política e a educação. Lessa admite que, em alguns momentos, o trabalho e a educação podem possuir alguma aproximação, todavia destaca que, quando alguém conta uma história para uma criança, por exemplo, essa mediação educativa não possui nenhuma relação com o trabalho. Embora eles possuam teleologias, isso não os identifica e muito menos pode fazer com que o trabalho seja princípio para a educação.

Não é somente essa crítica, todavia, que Lessa faz. Lembra ainda que a concepção de trabalho não-material é de difícil sustentação, na medida em que isso retoma uma concepção idealista entre o material e o não-material. Na concepção marxiana não caberia essa dicotomia, haja vista que as ideias são entendidas como força material e 
não o contrário, como caracteriza Saviani. Outra crítica incisiva que Sérgio Lessa faz a Saviani diz respeito ao engano da possibilidade de uma formação omnilateral ser realizada sob a égide do Capital. Nesse ponto, Saviani não está sozinho. A falta de entendimento de que, na atualidade, vivemos uma intensificação da alienação/estranhamento com o aumento da produtividade fez com que muitos pedagogos de esquerda não percebam a transformação atual do capital, a qual intensifica as crises. Fica evidente que, em tais circunstâncias, a proposta revolucionária é diluída em torno de políticas com distribuição de renda. Lessa (2007) entende que, mesmo com autores da esquerda nacional, assistese a um adeus ao proletariado.

Tais críticas começaram a nos indicar algumas desconfianças sobre a Pedagogia Histórico-Crítica. Daí, começamos um levantamento e localizamos uma dissertação de Mestrado em Educação de Carlos Eduardo Vieira, orientada pela professora Mirian Jorge Warde em 1994 na PUC - SP. Notemos que a professora Mirian Warde também foi uma das orientandas de Saviani na mesma instituição. A dissertação de Vieira analisa o caráter idealista da apropriação de Gramsci na educação brasileira. Nela, também há críticas à adoção que Saviani fez de alguns conceitos de Gramsci, como a Catarse. Vieira (1994) destaca que a ideia de catarse em Gramsci não se trata de uma ruptura individual, como sinalizada por Saviani. mas sim um

[...] momento ético-político da classe operária [...] a atividade política da classe levada às últimas consequiências. Consciência individual e consciência de classe não estão dicotomizadas, todavia o movimento histórico está na ação das classes e esse é o conteúdo que o marxismo concebe como teoria da revolução [...]" (Vieira, 1994, p. 95)

Porém, o principal alerta que Vieira nos deu foi sua crítica aos procedimentos formais das pesquisas na educação que se apropriavam de Gramsci para o entendimento dos problemas educacionais brasileiros e com as respectivas indicações de sua superação. Isso se deve à "rebeldia da realidade que teima em desobedecer aos modelos explicativos." (Vieira, 1994, p. 232). A crítica que Vieira fez a respeito da rebeldia da realidade é um problema a que os educadores e educadoras progressistas, de esquerda, anarquistas, socialistas ou comunistas precisam se ater.

Ainda levantando as análises críticas feitas a Saviani, encontramos uma que se fez não pelo campo da esquerda, como localizamos até aqui. Trata-se da obra de Lúcia Aranha (1992). A autora fez um levantamento de outros autores que analisaram criticamente os pressupostos pedagógicos de Saviani e encaminhou que, por vivermos em uma sociedade complexa, os pressupostos do materialismo histórico, tanto de Saviani quanto de seus críticos, seriam inadequados para entender a realidade e a própria educação. Acrescenta que enquanto observarmos que o aumento da riqueza no 
atual modo de produção e reprodução social impõe, de forma combinada e contraditória, o acúmulo de miséria, a lei do valor-trabalho de Marx e outros pressupostos ainda são válidos para o entendimento da realidade produtiva da humanidade na atual sociabilidade. Quando o trabalho alienado/estranhado, o capital e o Estado forem suprimidos, assim como as classes sociais, aí sim os pressupostos marxianos estarão definitivamente superados. Oxalá.

Contudo, tal superação parece estar longe e cada vez mais difícil. Mas isso não inviabiliza a saída prática marxiana para os atuais males sociais ${ }^{1}$. Embora a autora indique uma análise da qual discordamos, não podemos negar o levantamento feito por ela dos críticos de Saviani. Dentre eles, uma tese de doutorado em Educação escrita por Luzete Adelaide Pereira, em 1985, também orientada pela professora Mirian Jorge Warde, na Unicamp. Pereira (1985) já nos advertia quanto a problemas na concepção de Estado por parte de Demerval Saviani. Ao apontar a sua pedagogia revolucionária para intervir na realidade com ausência de uma crítica rigorosa ao Estado, conforme realizada por Marx, Lênin e Gramsci, Saviani deixa implícito que somente a luta pela socialização do saber na escola para os filhos da classe trabalhadora seria o suficiente para que, pouco a pouco, o Estado atual fosse superado.

Logo em seguida, deparamo-nos com uma crítica realizada por Guaraciaba Aparecida Tullio em sua dissertação de mestrado em Educação, da UNIMEP, em 1989. Nossas desconfianças, apoiadas em Mészáros $(2002,2005)$, foram validadas por esse trabalho realizado há cerca de 20 anos. Naquele momento, tentara-se objetivar a Pedagogia Histórico-Crítica na cidade de Curitiba - PR, mas nenhum estudo da prática escolar dos professores dessa época fora realizado. Somente um estudo dos documentos e dos currículos, a fim de verificar se guardavam alguma coerência com os pressupostos da Pedagogia Histórico-Crítica. Tullio (1989) faz uma análise do caminho do pensamento de Demerval Saviani, e indica uma pista de um dos pressupostos que Saviani possuía e que notamos, agora, serem compartilhados por muitos de seus orientandos. A professora Guaraciaba Tullio afirma que Karl Marx e Friederich Engels analisaram criticamente a produção, a distribuição, a circulação, o consumo e a apropriação das mercadorias na sociedade capitalista. Contudo, o aspecto fundante da crítica de Karl Marx e Friedrich

1. Lembremos o que Magalhães e Silva Júnior nos asseveram (2009): Levantar o socialismo como finalidade para a humanidade pode ser considerado um ato jurássico em virtude da derrocada do "Socialismo Real". Essa experiência que a União Soviética liderou com a Revolução Russa não pode ser considerada uma experiência socialista, mas sim pós-capitalista (Mészáros, 2002). Uma experiência socialista, além de extinguir a propriedade privada dos meios de produção, liquidará com o trabalho estranhado, com o Estado e com o capital. Não pode haver hierarquia entre os homens e mulheres. Nada disso aconteceu na União Soviética e com os seus congêneres. Logo, ter o socialismo como finalidade para a sociedade, além das extinções acima mencionadas, visa à formação de um ser social humano nãocoisificado, diferentemente dos pressupostos na égide do capital ou do pós-capitalismo. 
Engels está na produção, ou seja, no trabalho. É justamente nesse aspecto fundante que Marx e Engels estavam propondo uma revolução radical, assim como de toda a sociabilidade que dela possui mediações, e também como algum grau de independência. A partir dessa interpretação, a professora Guaraciaba Tullio nos indica que, ao desconsiderar o aspecto fundante da obra marxiana, Saviani, ao invés de centrar fogo em todas as fases do atual modo de produção, fez críticas somente à distribuição. Fica evidente uma unidade nos estudos feitos por Pereira em 1985 e Tullio em 1989.

Saviani, apesar da crítica severa à distribuição feita por Marx e Engels, "aposta" que a escola deva lutar pela distribuição do saber sistematizado pela humanidade. Frente a esta postura, as duas autoras perguntam: isso é possível no atual Estado regido pelo capital? Lessa (2007) já nos disse que não. Supõem as autoras que há uma preocupação com os problemas imediatos da educação, o que o faz se afastar da própria história que produziu esses problemas. Suas críticas possibilitam entender que predomina um reformismo moral, social e pedagógico, o qual se traduz em ações para intervenção nos problemas cotidianos imediatos. Isso faz com que uma proposta "popular" e uma proposta do capital não consigam se afinar, sendo a primeira derrotada. A forma "gelatinosa" que Tullio nota ser o tom de apropriação feita a Karl Marx por muitos autores críticos, entre eles Demerval Saviani, fez com que os mesmos se afastassem daquilo que acreditavam estar próximos, da História, e, consequentemente, afastaram-se dos aspectos fundantes do indivíduo e da sociedade.

Diante dessas duras críticas, nossas desconfianças quanto ao tratamento idealista concedido aos desafios educacionais por parte de Saviani $(2008,2007,2003,1994)$ começaram a provocar reflexões sobre o significado da Pedagogia Histórico-Crítica.

Desde a década de 1970, vivemos uma reestruturação produtiva ante a crise estrutural do capital, a qual vem aumentando a produção de valores de uso para a humanidade de forma combinada com o aumento da miséria humana. Essa produção destrutiva exigiu não só a reestruturação produtiva, como a reestruturação das políticas do Estado, entre elas a educação. Com a produção sob a égide da qualidade total, do just in time, dos estoques mínimos, juntamente com o fordismo, no Brasil adotou-se o modelo de produção toyotista. Embora se tenha acentuado o processo de demissões no país na década de 1980 e 1990, é possível observar que, de forma combinada, formou-se um trabalhador polivalente, competente-qualificado, e um trabalhador informal sem a necessidade de ser polivalente e tão qualificado. Agora, no ramo produtivo, os trabalhadores, ao invés de terem uma função como na produção fordista, assumem outras duas ou três funções em máquinas informatizadas, o que gera maior produtividade e exige menos trabalhadores. Isso pode ser observado com as demissões no setor bancário, chegando a 800 mil trabalhadores na década de 1990 (Antunes, 2006). 
Histórica e predominantemente, o Estado defende o Capital. Desse modo, diante desse pressuposto, István Mészáros (2005) indica que a educação faz mediações com valores. Em Cuba, os livros didáticos produzidos no período anterior à Revolução Cubana tratavam os Estados Unidos como uma nação importante para o desenvolvimento da humanidade. Contudo, Fidel Castro problematizou essa situação. Nós perguntamos: Em que sentido? Resgatou-se um período da história que Karl Marx caracterizou como a Acumulação Primitiva no Capital. Data desse momento a legislação sanguinária na Inglaterra de Henrique VIII no século XVII. Cerca de 72.000 pessoas foram condenadas à morte em virtude de suas "condutas preguiçosas" conduzirem-nas a roubar. Assim, algumas legislações foram sugeridas nesse momento. Entre elas destacamos que, se um indivíduo fosse pego pedindo esmolas sem autorização nos arredores de Londres, teria sua orelha cortada. A fim de refinar a legislação e torná-la mais "eficiente", John Locke propôs que as duas orelhas fossem cortadas. Aqui, observamos do que a burguesia foi capaz para legislar a seu favor ao tratar as consequências da miserabilidade humana desprovidas de suas reais causas. Desse modo, as instituições educacionais se adaptaram às determinações reprodutivas do Capital. Logo, a brutalidade pública física para tratar os desvios foi-se reduzindo com o aumento da brutalidade subjetiva promovida pela alienação/estranhamento. Lembramos o desespero que os pais possuem para lidar com os filhos, assim como os professores com os alunos. Locke propôs uma escola profissionalizante para os filhos das camadas ordeiras e submissas; dicotomizada, diferenciada da educação dos filhos da burguesia.

Nesse sentido, as instituições educacionais são acomodadas, predominantemente, ao projeto do Capital. Mesmo algumas boas intenções, oriundas de soluções formais, não são capazes de enfrentar a lógica do Capital: "Romper com a lógica do capital na área da educação equivale, portanto, a substituir as formas onipresentes e profundamente enraizadas de internalização mistificadora por uma alternativa concreta abrangente" (Mészáros, 2005, p. 47).

Desse modo, de forma muita sucinta, apresentamos que os interesses do trabalho são opostos aos interesses do Capital ${ }^{2}$. Enquanto este preconiza a hierarquia, a alienação/estranhamento, observamos que a história do tempo passado retorna ao tempo presente como um fantasma Haja vista que, nos anos de 2002, 2003 e 2004, houve uma redução nos investimentos da Educação em relação ao produto interno bruto - PIB (Leher, 2005) no Brasil.

Observa-se que o sistema público de ensino, ao ser pressionado pelas demandas do Capital, tem os seus recursos financeiros dilacerados. Estudioso de Karl Marx, Mészáros

2. Cf.: http://www.divida-auditoriacidada.org.br/config/artigo.2009-03-05.5210571984/document_view, acesso em 10 mar. 2009. 
entende que a superação das classes sociais é necessária para a liberdade humana. Por isso, afirma que uma educação para além do capital deve estar atrelada ao projeto de superação radical da economia, da política e da sociabilização sob a égide do capital. Para o autor, não há possibilidade de controle ou reforma do capital: "Educação para além do capital implica pensar uma sociedade para além do capital." (Mészáros, 2005, p. 13)

Assim, nos perguntamos: há possibilidade de continuidade de políticas educacionais que atendam aos interesses da classe trabalhadora predominantemente? É possível haver, sob a égide do capital, um sistema de educação de qualidade para todas as crianças matriculadas na escola pública? É possível organizar as escolas públicas para que todas as crianças possam se apropriar da cultura clássica sob a égide do capital? Seria possível a implantação de Escolas Politécnicas, ou Tecnológicas, para todos os filhos da classe trabalhadora sob a égide do capital?

Caso não façamos esses questionamentos difíceis, caso não façamos as reflexões com base nas condições objetivas que, na atualidade, produzem os valores de uso necessários para a humanidade e, de forma combinada, ainda continuam aumentando a miserabilidade que atinge quase $2 / 3$ da humanidade nesse momento, podemos acreditar, que sob as atuais condições, será possível o investimento de 7\%,8\% ou 10\% do PIB na educação. Contudo, lembremos o dizer da professora Acácia Kuenzer (2002, p. 94): “Esta [pedagogia emancipatória] vem sendo produzida ao longo da história nos espaços das contradições, mas só existe como possibilidade, a se objetivar em outro modo de produção, em que se estabeleçam as condições de igualdade, unitariedade e justiça social".

Há uma continuidade das políticas educacionais sob a égide do capital. Elas promovem a inclusão excludente. Notamos uma "empurroterapia" (Kuenzer, 2002, p. 93) sem padrões de qualidade educacional para os filhos da classe trabalhadora. Observamos que as escolas estão organizadas, observamos que há um sistema de educação, observamos que há políticas educacionais, todas elas atendendo ao atual modo de produção, predominantemente. Preconizar a mudança da escola, de políticas educacionais, sem indicar a necessidade de alteração do modo de produção, pode induzir ao pensamento de que há possibilidade de organizar a educação, com qualidade e de forma predominante, sem alterar as bases fundantes desta sociedade. Isso nos parece que seria uma solução formal. Diante disso, Ivo Tonet ressalta que:

Os "progressistas" (...), entendem que são as políticas neoliberais as responsáveis pelo agravamento dos problemas da humanidade. Outras políticas poderiam levar à construção de uma sociedade mais justa e igualitária. Isto mostra que esta segunda resposta pressupõe aquilo que antes afirmamos ser inviável: a possibilidade de controlar a lógica mais profunda do capital. Supõe que "um outro mundo é possível", "uma outra educação é possível" sem, contudo, exigir a superação radical do capital. (Tonet, 2007, p. 29) 
Quando nos deparamos com indicações de continuidades de políticas educacionais sem especificar a necessidade de alteração do modo de produção, conforme preconizado pela professora Acácia Kuenzer (2002), ou sem a exigência da supressão radical do capital (Tonet, 2007, 2005 a, 2005 b; Mészáros, 2005), indica-se que há possibilidade de organizar outra política educacional mantendo-se o atual modo de produção ${ }^{3}$. Isso talvez seja possível em alguns espaços, em algumas escolas, ou com muita dificuldade na objetivação de uma prática escolar em algum município; contudo, uma política educacional com qualidade dificilmente será predominante sob a atual reprodução econômica e social. Até porque, como indica Mészáros (2005), o capital é uma força incontrolável:

[...] de fato, da maneira como estão as coisas hoje, a principal função da educação formal é agir como um cão-de-guarda ex-officio e autoritário para induzir um conformismo generalizado em determinados modos de internalização, de forma a subordiná-los às exigências da ordem estabelecida. 0 fato da educação formal não poder ter êxito na criação de uma conformidade universal não altera o fato de, no seu todo, ela estar orientada para aquele fim. Os professores e alunos que se rebelam contra tal desígnio fazem-no com a munição que adquiriram tanto dos seus companheiros rebeldes, dentro do domínio formal, quanto a partir da área mais ampla da experiência educativa "desde a juventude até a velhice". (Mészáros, 2005, p. 55-56)

É possível inferirmos que Saviani, ao apontar os desafios pedagógicos, oferece indícios de um afastamento da realidade, das condições objetivas, chegando àquilo que Ivo Tonet nos alerta a respeito de algumas teses progressistas, ou seja: a política neoliberal. Acreditamos que István Meszáros indica, objetivamente e de forma radical, os desafios da educação na contemporaneidade: sem uma emancipação do trabalho não há como pensarmos numa emancipação da educação. Aqui, parece que temos outra "chave" para pensarmos a educação com a concepção marxiana. Ao invés de discutirmos se a educação é politécnica ou tecnológica, parte-se daquilo que atravessa a obra marxiana, desde A Questão Judaica até a obra 0 Capital: a emancipação humana, a liberdade. Essa é a teleologia que guia István Mészáros para tratar dos desafios da educação. 0 contrário, conforme observamos em Demerval Saviani, faz-nos ter uma preocupação com políticas educacionais que possam implementar uma escola politécnica ou tecnológica e a própria Pedagogia Histórico-Crítica.

Entendemos que os autores possuem os mesmos pressupostos, contudo meios distintos para tratar dos desafios da educação. A preocupação com a emancipação humana traz em si uma preocupação com a nossa prática, a preocupação de termos,

3. Vejamos o que nos asseveram José Paulo Netto e Marcelo Braz (2007, p. 139): "Imaginar a 'solução' da 'questão social' mantendo-se e reproduzindo-se o MPC [modo de produção capitalista] é o mesmo que imaginar que o MPC pode se manter e se reproduzir sem a acumulação do capital". 
além de uma epistemologia de esquerda, uma ética também de esquerda. Isso é extremamente difícil. Mas, sob a atual égide do capital, onde o novo ainda não nasceu e o velho ainda não morreu, ou ainda com a humanidade vivendo a pré-história, ao invés da verdadeira história dos sujeitos livres, István Mészáros parece conclamar que educadores tentem buscar essa coerência ao máximo em sua prática e, além disso, associem-se aos movimentos extraparlamentares visando à política radical ${ }^{4}$.

Quando Demerval Saviani aponta os desafios pedagógicos atuais la ausência de um sistema de educação, a necessidade de organização das escolas e as descontinuidades de políticas educacionais), parece que a alteração radical da educação, conforme é alentada pelo autor ${ }^{5}$, é um desafio que tem o início de sua superação com as políticas educacionais, caso sejam contínuas. Isso seria possível mantendo-se o atual modo de produção? Acácia Kuenzer já nos disse: não. Daí estarmos problematizando os desafios pedagógicos indicados por Saviani; porque agora, assim como nos anos anteriores, essa tese tratada pelo autor é retomada sem alteração significativa de sua exposição. Pensamos que o caminho do pensamento de Demerval Saviani afasta-se da prática social inicial, das condições objetivas da realidade, as quais o próprio autor defende. Diante disso, acreditamos que os desafios pedagógicos apontados por Saviani transmitem-nos a ideia de que podemos iniciar uma educação de qualidade e que a mesma pode ter continuidade sob o atual modo de produção. Fato que pensamos se aproximar daquilo caracterizado por István Mészáros como uma solução formal.

Acreditamos que, quando o professor Demerval Saviani faz uma crítica às pedagogias da essência e da existência e propõe a Pedagogia Revolucionária, logo a seguir designada como Pedagogia Histórico-Crítica, apropria-se, de forma moral e idealista, de alguns conceitos de Marx e de Gramsci, tornando-os pressupostos idealistas na Pedagogia Histórico-Crítica, dentre eles a ausência de um entendimento da prática escolar dos professores na realidade cotidiana. 0 debate teórico com a pedagogia tradicional, a pedagogia tecnicista, a pedagogia escolanovista o fez se afastar de uma própria hipótese sua, a qual caracterizava a formação docente como escola novista, mas em contraste tanto com a existência de uma legislação tecnicista quanto com condições de trabalho cujos pressupostos da remetem à escola tradicional. Essa tese do autor, entendemos, poderia ter sido problematizada. Nela, reside uma indicação para que se compreenda o professor na sua cotidianidade. Fato que Saviani não o fez em virtude de suas pesquisas se aterem, notadamente, ao campo teórico.

4. Vejamos o que nos assevera István Mészáros (2006, p. 119): "o tipo conservador de mediação política procura maximizar o elemento de continuidade em suas tentativas de ligar o presente com o futuro, ao passo que a política radical dá ênfase à descontinuidade, evidentemente".

5. Lembremos que o professor Demerval Saviani é enfático no pressuposto de que defender a escola pública de qualidade significa defender o Socialismo. 
Indicações de pesquisa empírica no cotidiano escolar são reclamadas por Gonzalez (2006) e Silva Júnior e Ferretti (2004). Isso corrobora a dissertação de Vieira (1994) a respeito da rebeldia da realidade. As contradições postas na realidade pelas condições objetivas de trabalho docente e pelas condições objetivas de trabalho dos pais e mães das crianças matriculadas nas escolas públicas parecem intensificadoras dos problemas educacionais nas últimas décadas, em virtude de uma crise estrutural do capital. Transferindo o problema para a superestrutura, promove-se a reforma do Estado e se intensifica uma racionalidade pragmática e um senso comum que preconiza a História estar dada e não haver mais o que fazer, cabendo ao mérito individual a condição de saída da miserabilidade.

Portanto, além das condições contraditórias em que se encontra a classe docente, muito bem destacadas por Saviani (ser formado numa dada perspectiva, ter uma legislação educacional contrária a essa e uma escola cuja orientação para o desenvolvimento pedagógico se situa numa concepção ainda distinta das duas), a objetivação de uma Pedagogia Histórico-Crítica pressupõe muito mais do que uma adoção didática ou metodológica, conforme sugere Gasparin (2002). As professoras querem ensinar. Elas querem aprender conteúdos. Contudo, a sua epistemologia e sua ética talvez não sejam de esquerda. Será que alguma política pública é capaz de fazer com que os professores consigam repensar seus valores, suas ideias e sua concepção de mundo? Para objetivar a Pedagogia Histórico-Crítica, parece que o primeiro passo seria "combinar" com o professor que ele tenha ao menos uma epistemologia de esquerda. Mas isso se faz num tempo curto, médio ou longo? A formação da consciência de classe do professor farse-á com alguma continuidade de política pública? Aqui, há um grande pomo de discórdia em que todos se desencontram. Os professores da escola se encontram com o idealismo das Secretarias Municipais de Educação, as Secretarias Municipais de Educação se encontram e se desencontram com as propostas educacionais, e a Pedagogia Histórico-Crítica se desencontra com professores na realidade e com as atuais condições de produção e reprodução social.

\section{Desafios da prática escolar na cotidianidade com base na Pedagogia Histórico-Crítica}

Durante a pesquisa realizada por nós em uma cidade no interior do Paraná, com cerca de 80.000 habitantes, observamos uma reunião organizada pela Secretaria Municipal de Educação com as orientadoras educacionais das escolas, para sistematizar a avaliação do primeiro semestre de 2008. Vale destacar que esse município tentou 
objetivar sua prática escolar com base na Pedagogia Histórico-Crítica entre os anos de 2001 e 2008 sob a gestão do Partido dos Trabalhadores (PT). As orientadoras educacionais foram informadas que a avaliação da Secretaria Municipal de Educação seria em julho de 2008, enquanto a avaliação Prova Brasil, do Governo Federal, seria em novembro de 2008.

As assessoras da Secretaria Municipal de Educação informaram que, em reunião com as orientadoras educacionais, a disciplina matemática fora mencionada como aquela em que alunas e alunos apresentavam maior dificuldade. Por isso, elas começariam a reunião discutindo a sistematização da avaliação dessa disciplina. Nesse momento, as orientadoras educacionais começaram a citar suas sugestões ao roteiro de elaboração da avaliação. Sugeriram que os enunciados das avaliações tratassem do sistema monetário, problematizando os preços de brinquedos e também os preços de outras mercadorias, e sugeriram também a elaboração de gráficos em que fossem discutidas as distintas alturas de jogadores em uma equipe. As outras escolas também destacaram a questão monetária. Seja com a elaboração de enunciados que tratassem da oferta de produtos em supermercados, seja com medidas de comprimento para serem tratadas com os alunos e as correlações entre distintos sistemas de medidas (metro, polegadas, pés, jardas).

Notamos uma discussão dos conteúdos sem a problematização dos valores, das concepções de mundo que orientam a elaboração da avaliação. A discussão da avaliação de língua portuguesa indicou textos que tratavam da necessidade de economizar água, o desperdício de água, o aumento de consumo da água, enfim, de uma série de problemas ecológicos. Outro conjunto de questões fazia referência a textos que tratavam da alimentação: da necessidade de uma alimentação saudável, da necessidade de uma dieta balanceada, enfim, da "qualidade" da alimentação. Nesse momento, uma orientadora educacional indicou uma poesia (Carlos Drumond de Andrade). Uma orientadora educacional, de outra escola, ponderou que seria uma questão muito difícil por causa do tipo de conteúdo. Relatou que as crianças não possuíam o hábito de fazer avaliação e aquele conteúdo seria de extrema dificuldade para os alunos das escolas municipais entenderem e responderem.

Observamos que as discussões possuíam uma espontaneidade no trato da elaboração dos enunciados na medida em que as questões ideológicas não eram tratadas. Contudo, não é somente isso que estamos refletindo. No único momento em que uma orientadora educacional apontou um clássico da literatura como questão de uma avaliação, vimos outra orientadora educacional afirmar que aquilo seria uma leitura muito difícil para as crianças do município. 0 que caracterizamos desse momento é que legitimamos uma avaliação com enunciados de fácil entendimento porque as nossas crianças são "pobres". Eles são filhos da classe trabalhadora precarizada. Seus pais recebem cerca de dois salários mínimos, suas mães são empregadas domésticas, 30 \% dos alunos são oriundos 
de famílias que recebem bolsa-família. Nesse momento de observação, pensamos: agora elas vão começar a discutir: quem são as suas crianças? Quais são as condições fundantes na formação social das crianças desse município? Enfim, a realidade viria ao pensamento. Mas nada disso aconteceu. Somente ouvimos que aquele texto não era apropriado para as crianças do município porque era muito difícil. Ou seja: para os filhos da burguesia ou para aqueles que conseguem pagar uma escola privada para os seus filhos (que exija a apropriação dos conteúdos clássicos), ou para escolas públicas como o Pedro II, no Rio de Janeiro, e alguns Colégios de Aplicação no Brasil, a apropriação dos conteúdos clássicos é sim exigida, e nenhum professor reduz essa possibilidade. Isso independente de sua ideologia ser contra ou a favor do capital. Mas, para as crianças pobres, deve ser selecionado também um enunciado "pobre".

Isso precisa ser problematizado. Afinal, já aprendemos que as classes dominadas são ensinadas a pensar com as ideias produzidas pela classe dominante. Ter o pressuposto de que as crianças são "pobres" e isso justifica a necessidade de utilizar textos "pobres" não é do interesse de uma pedagogia de esquerda ou de uma prática escolar emancipatória. É importante ressaltar que ainda pensamos predominantemente com as ideias que são produzidas pela classe dominante. Parece que não basta proclamar uma pedagogia dita crítica como base para a fundamentação de uma prática escolar revolucionária. Problematizar a nossa história é fundamental. Caso contrário, não conseguimos fazer uma autoavaliação do que somos, ou melhor, daquilo que deveríamos ser.

Afirmamos cada vez mais o nosso estranhamento com relação a práticas que se embasam em iniciativas ou na boa intenção de uma Secretaria Municipal de Educação, tomando posse dessa responsabilidade e na tentativa de superar o problema da baixa qualidade de ensino na rede pública, mas sem a devida radicalidade para entender esse processo, pois o resultado é que não se consegue dar sequer os primeiros passos para uma breve suspensão do problema, provocando um ensino com maiores conflitos. Ao contrário, contraditoriamente, reafirma-se tudo aquilo que se "nega".

Durante essa reunião, a elaboração da avaliação parecia não estar próxima àquilo que seria a intenção: a Pedagogia Histórico-Crítica como base da prática escolar naquele município. Caso estejamos corretos, a Pedagogia Histórico-Crítica defende a apropriação da cultura clássica da humanidade, e para isso problematiza a prática social inicial dos alunos a fim de chegar a uma síntese superior quando apropriada aquela cultura.

Para a avaliação do segundo ano do segundo ciclo ( $4^{\mathrm{a}}$. série), fora escolhido um texto que discutia uma a mudança de paisagem natural após a instalação de fábricas. Ao lado da floresta poluída, havia uma cidade. 0 prefeito pediu que fossem procurados donos de empresas importantes para fundar empresas na cidade. Após a vinda das fábricas, a floresta foi mudando e a quantidade de casas aumentou, assim como a poluição local. 
Embora o texto faça uma caracterização de um problema grave que vivemos na atual reprodução social, sua explicação e a análise dos fatos mencionados sugerem que o problema está nas fábricas. Muito pelo contrário. 0 aumento da produção de valores de uso para a humanidade é condição sine qua non para a conquista de nossa liberdade. Produzir sem agredir o meio ambiente é uma possibilidade real para a humanidade. Todavia, a atual produção destrutiva desconsidera a qualidade ao produzir produtos que duram menos tempo, ao tratar bens esgotáveis como se fossem inesgotáveis. Se a escola desconsidera a classe dominante como a responsável pela produção destrutiva, isso explica o fato de forma ideal e sugere uma análise idealista de um dos problemas que afligem a realidade.

Não estamos sugerindo que deva haver um comitê central a dizer qual deve ser a literatura para os filhos da classe trabalhadora. Os clássicos estão postos e alguns até recebem prêmios, como o Jabuti, no Brasil; e há, ainda, o caso de autores anticomunistas que conseguem caracterizar o cotidiano de forma clássica, como Nélson Rodrigues ${ }^{6}$. Mas cremos que, se não oportunizamos que uma criança leia na escola o poema "0 Açúcar", de Ferreira Gullar, essa criança dificilmente conseguirá estudar esse poema no seu cotidiano extraescolar. Parece que nos afastamos cada vez mais do que é proposto pela Pedagogia Histórico-Crítica.

Lutar por conquistar uma visão de mundo histórica, contra o senso comum, que tensione não só a ideologia, mas a atual relação social de produção, ou até a própria cotidianidade e sua respectiva sociabilidade é de fundamental importância para que possamos ter breves suspensões do limiar de mediocridade cotidiano e problematizemos não somente as consequências dos atuais problemas sociais existentes, mas sim as suas causas. Isso nos deixará em conflito permanente. 0 movimento em si e para si terá maiores conflitos, exigindo cada vez mais uma política radical para a sua superação.

Ainda a respeito da avaliação do segundo ano do segundo ciclo ( $4^{\mathrm{a}}$. série), embora o texto suscite explicações e análises inconsistentes, poderíamos esperar que as questões tratassem de uma reflexão radical do conteúdo proposto. Mas a primeira pergunta da prova estabelece uma relação de causa e efeito, pedindo para indicar quais eram os parágrafos do texto que se referiam à floresta. Logo a seguir, pergunta o que o Prefeito considerava importante para a cidade. Mais adiante, indaga-se sobre o motivo que levou o prefeito a solicitar que seu secretário procurasse indústrias para a cidade. Por fim, perguntava-se a respeito das mudanças na qualidade de vida das pessoas. As respostas, em sua maioria, consistiam em que o aluno fosse capaz de copiar o trecho que dava continuidade ao verbo imperativo da pergunta localizado no próprio texto. Novamente,

6. Isso precisamos frisar para que não sejamos condenados por estar indicando uma nova censura stalinista à arte. 
parece-nos haver um distanciamento do que é proposto pela Pedagogia HistóricoCrítica. A sistematização dessa avaliação não apresenta fatos que indiquem que exista uma preocupação com a apropriação da cultura clássica desenvolvida pela humanidade, e também parece bem afastada de uma consciência social que indique uma polêmica com a prática social inicial, com a formação em-si.

$\mathrm{Na}$ avaliação de matemática, das crianças do segundo ano do segundo ciclo $14^{\mathrm{a}}$. série), identificamos várias mercadorias nos enunciados. Renda branca, sapatos femininos e masculinos de uma loja, preços de mercadorias, enfim, tudo aquilo relacionado ao trabalho abstrato na atual reprodução social. Entretanto, entendemos que os enunciados dessa disciplina, assim como na avaliação da língua portuguesa, estabeleciam uma relação de causa e efeito que se afasta de uma reflexão sobre a prática social inicial dessas crianças e dos professores no município. Pensamos como poderia ser sido problematizada a avaliação de matemática para que houvesse uma análise da prática social inicial, porque avaliamos que o aporte da economia-política é necessário. Observamos que as orientadoras educacionais indicaram questões sobre o sistema financeiro para serem tratadas nas avaliações. Todavia, isso não pode se restringir à apresentação do preço de um metro de produto ou a perguntas sobre qual é o preço pago na compra de $15 \mathrm{~m}$ de um produto. Pensamos no seguinte exemplo: um trabalhador da Ford na Bahia recebe cerca de $\mathrm{R} \$ 0,80$ por cada carro produzido hoje, e que será vendido pelo valor de $\mathrm{R} \$ 30.000,00$. Ele possui um salário de cerca de $\mathrm{R} \$ 500,00$, enquanto o lucro da fábrica de Camaçari, na Bahia, em 2001 foi de quatro bilhões de reais. Quantos anos 500 trabalhadores dessa empresa precisariam trabalhar para ter em sua conta quatro bilhões, recebendo cerca de $\mathrm{R} \$ 500,00$ por mês?

E multiplicam-se as mercadorias que podem ser abordadas. Destacamos a canade-açúcar. Um canavieiro recebe cerca de $\mathrm{R} \$ 4,00$ por tonelada de cana-de-açúcar cortada. Em média, ele corta 10 toneladas por dia. No ano de 2008, na região de Ribeirão Preto, foram produzidas cerca de 140 milhões de toneladas de cana-de-açúcar. 0 preço de cada tonelada de açúcar é cerca de $\mathrm{R} \$ 40,00$. Quanto ganha por mês um trabalhador que mora numa casa de $60 \mathrm{~m}^{2}$, e quanto ganha um fazendeiro que possui $400.000 \mathrm{~m}^{2}$ ? Outra questão possível seria: quanto tempo um trabalhador do corte de cana de açúcar levaria para comprar uma colheitadeira no valor de $\mathrm{R} \$ 250.000,00$ ? Pode-se, ainda, sugerir que as crianças façam contas sobre uma família cuja média salarial é de dois salários mínimos, e os pais possuem duas alternativas no fim do mês: pagar o aluguel de $R \$ 300,00$ ou comprar comida com os mesmos $R \$ 300,00$. Essas contas precisam ser feitas por nossas crianças nas escolas. Elas somente iniciam a problematização da prática social inicial. Essas são as questões que, imaginamos, começariam a problematizar o trabalho, a riqueza, a produção, a circulação, a distribuição e o consumo na atual sociedade. 
Os exemplos se multiplicam; basta ler o jornal "O Valor" e dele extrair diversos fatos matemáticos que podem não só fazer com que haja domínio das operações fundamentais, bem como domínios dos fundamentos das operações fundamentais no capital.

Enfim, a seleção de conteúdos para ser ensinados às crianças, a escolha das atividades a serem elaboradas para as aulas e a sua organização ao longo de um bimestre, de um semestre e de um ano letivo é uma preocupação que observamos nas reuniões de planejamento. Justamente um dos pressupostos da Pedagogia Histórico-Crítica, os conteúdos, é aquilo que as professoras refletem em suas reuniões de planejamento e também é um fato destacado pela pesquisa de Cardoso (2006). Esta constatou que cerca de $50 \%$ das professoras iam às formações continuadas para aprender os conteúdos. Isso não pode ser desconsiderado. Esse fato nos indica que um trabalho de formação continuada com as professoras em um município precisará partir desse ponto também. As professoras precisam dominar o máximo possível do conteúdo a ser ensinado, independentemente de sua ideologia. Até porque já vimos que um anticomunista como Nélson Rodrigues é capaz de caracterizar com elevada consistência a vida cotidiana. E um fato que também aprendemos com José Paulo Netto (1998) é que uma obra como a Paidéia não foi escrita por um autor de concepção marxiana, mas é de extrema importância para qualquer pesquisador porque ela é um clássico.

Parece-nos que garantir que um professor consiga ter o máximo de domínio possível de um conteúdo a ser ensinado constitui-se numa prática revolucionária sob as atuais condições de produção e reprodução social na educação dos filhos da classe trabalhadora. Pensamos aqui com Lukács (1999) e Heller (1970, 2002), que nos indicam que a ciência, a filosofia, a moral, a política e a arte são algumas possibilidades que permitem às pessoas se suspender do seu limiar de mediocridade cotidiano e, ao retornarem para o cotidiano, começar a lutar contra ele e cada vez mais buscar a sua superação. Pensamos também que a arte, o esporte e a ciência são de fundamental importância para a educação dos filhos da classe trabalhadora. E caso consigamos que ela esteja articulada à história, ou seja, com valores e ideias que contestam a atual reprodução social, aí começamos a dar um segundo passo em direção a uma prática educativa emancipatória.

Quando afirmamos aqui segundo passo, não estamos dividindo esses dois momentos na formação docente para que o professor ou a professora acredite e possa objetivar uma prática escolar emancipatória. Isso terá que acontecer de forma combinada e vai acontecer de forma contraditória. Acreditamos que a problematização das ideias que precisamos ter para pensar a realidade talvez possam demorar mais tempo de serem contextualizadas, até porque exigiremos que seja contextualizada a nossa história de vida articulada de forma combinada e contraditória com a história da cidade, do país e da atual sociabilidade. E o processo de pensar contra o nosso pensamento e pensar 
contra a realidade são tempos distintos. Mas não deixamos de pensar no próprio Georges Lukács, que demorou acerca de 15 anos para se depurar do seu idealismo.

Não estamos aqui afirmando que esse é o tempo necessário para que possamos ter uma consciência revolucionária. Mas acreditamos que a realidade, a história são o motor para ampliar ou reduzir o tempo da necessidade de assumirmos uma consciência que vai nos exigir a adoção de uma política radical para a resolução dos problemas de uma prática escolar na cotidianidade, em que observamos uma prática social inicial, conforme descrito no projeto da escola por nós investigada, onde 30\% de crianças são de famílias que recebem bolsa-família, $25 \%$ de crianças têm pais analfabetos, e a renda mensal média da maioria das famílias é de dois salários mínimos. Vivemos um tempo confuso em que as contradições da atual reprodução social podem se intensificar. Sem significar, contudo, que esse sistema social será modificado. Muito pelo contrário. Existe uma possibilidade maior dele se perpetuar, acentuando as contradições e a intensificação da produção de riqueza com o aumento da produção de miséria. Ante tais constatações, lembramos o que nos advertiu Karl Henirich Marx em 1843:

É certo que a arma da crítica não pode substituir a crítica das armas, que o poder material tem de ser derrubado pelo poder material, mas a teoria converte-se em força material quando penetra nas massas. A teoria é capaz de se apossar das massas ao demostrarse ad hominem, e demonstra-se ad hominem logo que se torna radical. Ser radical é agarrar as coisas pela raiz. (Marx, 2005, p. 151)

Aqui, observamos um dos pressupostos que nos faz crer que a teoria é um dos elementos que, quando representada na ciência, por exemplo, pode permitir breves suspensões do cotidiano e incitar a luta pela superação deste. E ainda continuamos pensando com Karl Henirich Marx, agora junto com Friederich Engels, que nos disseram o seguinte em 1845:

[...] a verdadeira riqueza espiritual do indivíduo depende totalmente da riqueza de suas relações reais. Só através disso os indivíduos concretos se liberam dos diferentes grilhões nacionais e locais, põem-se em contato prático com a produção lincluindo a espiritual) do mundo inteiro e se colocam em condições de adquirir a capacidade necessária para poder desfrutar desta produção multiforme e completa de toda a terra (as criações dos homens) [sic]. (Marx; Engels, 2007, p. 61)

Aqui parece que temos uma pista de um pressuposto para uma aula. Explorar o máximo das relações reais que os alunos possam ter conosco em sala de aula é uma tarefa revolucionária na atual conjuntura, sabendo que as suas relações reais fora da 
escola são duras e que dificilmente serão alteradas, já que parece haver uma tendência de que as condições materiais, objetivas dos nossos alunos nas escolas públicas tornemse mais precárias, haja vista a tendência de uma precarização no trabalho (Antunes, 2006; Mészáros, 2002). Com isso, se as condições objetivas de reprodução das famílias das crianças matriculadas em nossas escolas públicas parecem se tornar mais precárias, se as condições de trabalho do professor parecem também que dificilmente podem se alterar significativamente, haja vista a administração política no município pesquisado (cujo salário de um professor em início de carreira não supera os $\mathrm{R} \$ 500,00$ por 20 horas de trabalho semanal), e dificilmente essas condições objetivas e de trabalho serão melhoradas por qualquer governo que mantenha o ajuste fiscal em detrimento do ajuste social. Sem a compreensão dessa realidade, o professor não tem força para enfrentar toda essa adversidade em sua sala de aula.

Ante esta problemática, a formação técnica e política precisa ser feita de forma combinada, e sua objetivação será de forma contraditória. Contudo, quando as professoras começam a perceber que uma mediação distinta pode produzir uma objetivação distinta, temos a chance de ter uma professora que entenda a realidade em sua radicalidade, percebendo que essa realidade dificilmente será modificada no atual tempo presente, o que, por isso mesmo, exige que nos esforcemos ao máximo por nossa formação na direção para si e, com isso, ampliemos os nossos conflitos, construindo o maior número possível de relações mais ricas em nossa sala de aula e fora dela. E essa formação para si será uma identidade grupal conquistada em organizações extraparlamentares que contestem a sociabilidade do capital em sua raiz.

Nesse município, governado por duas gestões do Partido dos Trabalhadores, constatamos que não foi a continuidade de uma política pública ou a sua falta que apresentou desafios para a objetivação da Pedagogia Histórico-Crítica. Considerando que os enunciados das avaliações tratavam de situações triviais, parece-nos que isso é a síntese de múltiplas determinações: tanto as condições objetivas para o desenvolvimento da prática escolar, quanto as condições históricas que promoveram a formação do ser social professor, e também as condições das políticas educacionais conservadoras do passado que voltaram ao presente (2001-2008) como um fantasma. Enfim, não é a implantação de uma política educacional que poderá alterar a objetivação de uma prática escolar. Somente uma política radical pode permitir a mudança dos aspectos econômicos e extraeconômicos que, de forma combinada e desigual, atuam no estranhamento do ser social - no caso aqui averiguado, o professor. 


\section{À guisa de conclusão}

Entendemos que a ausência de uma epistemologia de esquerda e uma ética de esquerda em um corpo docente constitui-se em um dos obstáculos para a objetivação da Pedagogia Histórico-Crítica. Todavia, isso não significa que o problema esteja localizado na prática escolar do professor, pois as idéias dominantes são produzidas pela classe dominante (Marx; Engels, 2007). Essa prática é a síntese de múltiplas determinações. Seja uma formação inicial inconsistente, formações continuadas também inconsistentes, seja a carga horária de trabalho superior a 40 horas com salários baixos; somese a isso as políticas educacionais que esvaziaram a escola de conhecimento científico em décadas anteriores, articuladas com "teorias" de motivação para o professor ser "competente", e ainda comente-se o baixo orçamento na educação brasileira, que nunca chegou a $10 \%$ do PIB. Todas essas condições objetivas de décadas anteriores voltam ao presente como um fantasma. Mesmo com duas gestões consecutivas em uma Prefeitura que tentou objetivar a Pedagogia Histórico-Crítica (Magalhães, 2010), observou-se que esse passado interfere na prática escolar cotidiana dos docentes, a ponto dos mesmos ainda não se sentirem seguros de ensinar a cultura clássica produzida pela humanidade com a sua respectiva problematização.

Assim, indicar que a Pedagogia Histórico-Crítica deva garantir a apropriação da cultura clássica produzida pela humanidade é uma teleologia coerente. Contudo, as condições fundantes da economia política sob a égide do capital permitirão financiamentos de cerca de 10\% do PIB na Educação? A resposta com Mészáros (2002, 2005), José Paulo Netto e Marcelo Braz (2007), e Francisco Oliveira (2008)7 indica-nos que, muito provavelmente, não. 0 Estado predominantemente defende o capital. Mesmo um Estado com característica neopopulista ou neoliberal. Assim, garantir a apropriação da cultura clássica exige que o corpo docente tenha as condições objetivas para dela se apropriar e com isso poder ensinar na sua prática escolar. Todavia, a cultura clássica ${ }^{8}$ hoje é uma mercadoria com valor de uso significativo e com poucos sujeitos com as condições objetivas de comprá-la. Com efeito, ao desconsiderar as condições fundantes da economia-política, as quais formam a mediocridade cotidiana (Carvalho, Netto, 2007) do professor, e considerando que basta mudar a política educacional, mantendo-se o

7. "A redistribuição de renda que Lula faz é a favor dos ricos e não dos pobres. São $R \$ 160$ bilhões anuais de juros da dívida pública interna, contra R 8 bilhões do Bolsa-Família" (Oliveira, 2008).

8. Pensamos nas escolas privadas com mensalidades em torno de $R \$ 2.000,00$ as quais ensinam o conhecimento científico para os seus alunos; pensamos, também, na apresentação do bailarino Mikhail Baryshnikov no Teatro Municipal do Rio de Janeiro com ingressos entre $R \$ 40,00$ e $R \$ 260,00$ (outubro/2010); numa mensalidade de Judô, alemão, inglês, ballet, capoeira custando em torno de $R \$ 150,00$. Esses valores contrastam com a realidade de um professor que por vezes trabalha cerca de 40 horas semanais para receber um salário médio de $R \$ 1.400$. 
atual modo de produção, a Pedagogia Histórico-Crítica, embora tenha uma intencionalidade importante, parece permanecer no plano das soluções formais.

Entendemos que uma educação de qualidade exigirá uma sociedade que tenha o trabalho também com qualidade, o que pressupõe os trabalhadores livres. Nesse sentido, exige-se que as mudanças sejam essenciais e não formais, conforme assevera István Mészáros (2005). Numa sociabilidade regida pelo capital, cabe à prática escolar emancipadora ensinar os conteúdos específicos de cada área, e além disso buscar um reconhecimento radical da economia-política capitalista, a qual elabora o desenvolvimento desigual e combinado de miséria e riqueza. Isso exigirá uma finalidade: formar humanos emancipados e livres. Importa lembrar, ainda, que a liberdade somente será alcançada com a redução da jornada de trabalho (Marx, 1991). A partir dessa finalidade os meios deverão ser organizados, assim como diversas alternativas elaboradas. Todavia, os valores que conduzirão essa prática escolar precisam ser aqueles organizados pela classe trabalhadora, o que por consequência exige-nos um estado de alerta para combinar uma epistemologia de esquerda com uma ética de esquerda em prol da superação do Estado, do trabalho alienado/estranhado e da superação do capital, articuladas por meio de uma política radical com os movimentos extraparlamentares.

Nesse sentido, a organização de uma prática escolar emancipatória não é feita por meio de ideias idealistas, pragmáticas ou irracionais. Sob a égide do capital dificilmente as condições de trabalho do professor serão melhoradas pelo Estado. Até porque o fundo público predominantemente socorre o Capital. Assim, objetivar uma prática escolar emancipadora exige lutar também por uma sociedade emancipada, a qual somente se objetivará com os trabalhadores e trabalhadoras livremente associados.

\section{Referências}

ANTUNES, Ricardo. A era da Informatização e a época da informalização. In: ANTUNES, Ricardo. (Org.) Riqueza e miséria do trabalho no Brasil. São Paulo: Boitempo. 2006. p.15-25.

ARANHA, Lúcia. Pedagogia histórico-crítica: o otimismo dialético em educação. São Paulo: EDUC, 1992. CARDOSO, Ana Maria. Um olhar sobre a formação continuada de professores na rede municipal de Sarandi. 2006. 138 f. Dissertação (Mestrado) - Programa de Pós-Graduação em Educação. Universidade Estadual de Maringá, Maringá, Paraná. 2006.

CARVAlHO, M. do C. de; NETTO, J. P. Cotidiano: conhecimento e crítica. São Paulo: Cortez, 2007.

GASPARIN, João Luiz. Uma didática para a pedagogia histórico-crítica. Campinas: Autores Associados, 2002.

GONZÁLEZ, Jorge Luis Cammarano. Sobre a educação para além do capital. In: ALVES, Giovanni; GONÁLEZ, Jorge Luís Cammarano; BATISTA, Roberto Leme. (Org.) Trabalho e educação: contradições do capitalismo global. São Paulo: Práxis, 2006. p. 115-145. 
GULLAR, Ferreira. Dentro da noite veloz \& Poema sujo. São Paulo: Círculo do Livro, s/d, p. 51-52. HELLER, Agnes. O cotidiano e a história. Rio de Janeiro: Paz e Terra, 1970.

Sociología de la vida cotidiana. Barcelona: Península, 2002.

KUENZER, Acácia Zeneida. Exclusão includente e inclusão excludente: a nova forma de dualidade estrutural que objetiva as novas relações entre educação e trabalho. In: LOMBARDI, José Claudinei; SAVIANI, Demerval; SANFELICE, José Luís (Org.). Capitalismo, trabalho e educação. São Paulo: Autores Associados, 2002. p. 77-95.

LEHER, Roberto. O público como expressão das lutas sociais: dilemas nas lutas sindicais e dos movimentos sociais frente ao desmonte neoliberal da educação pública. LPP-UERJ. 2005. Disponível em: <www.outrobrasil.net>. Acesso em: 10 mar. 2006.

LESSA, Sergio. Trabalho e proletariado no capitalismo contemporâneo. São Paulo: Cortez. 2007.

LUKÁCS, Georg. Pensamento vivido: autobiografia em diálogo: entrevista a István Eorsi e Erzsébet Vezér. São Paulo, Viçosa: Ad Hominem/Editora da UFV, 1999.

MAGALHÃES, Carlos Henrique Ferreira ; SILVA JÚNIOR, João dos Reis. Limites e possibilidades de apropriação da pedagogia histórico-crítica. Revista Educação, Unisinos, v.13, n. 1, p. 51-62, 2009.

Magalhães, Carlos Henrique Ferreira. Limites e desafios para objetivação da pedagogia históricocrítica na prática escolar. 2010. 233 f. Tese (Doutorado)-Programa de Pós-Graduação em Educação da Universidade Federal de São Carlos, UFSCar, São Carlos, 2010.

MARX, Karl. Crítica da filosofia do direito de Hegel. São Paulo: Boitempo, 2005.

MARX, Karl. O capital. Crítica da economia política. Livro Terceiro. VI. Rio de Janeiro: Bertrand Brasil, 1991.

MARX, Karl; ENGELS, Friederich. A ideologia alemã. Rio de Janeiro: Civilização Brasileira, 2007.

MÉSZÁROS, István. A educação para além do capital. São Paulo: Boitempo, 2005.

. Para além do capital. Rumo a uma teoria da transição. São Paulo: Editora da Unicamp/ Boitempo, 2002.

A teoria da alienação em Marx. São Paulo: Boitempo, 2006.

NETTO, José Paulo; BRAZ, M. Economia política: uma introdução crítica. São Paulo, Cortez, 2007.

NETTO, José Paulo. Os desafios epistemológicos e metodológicos da pesquisa histórica. In: SAVIANI, Dermeval; LOMBARDI, José Claudinei; SANFELICE, José Luís. (Org.) História e história da educação: o debate teórico-metodológico atual. Campinas: Autores Associados, HISTEDBR, 1998. p.11-26.

OLIVEIRA, Francisco de. Lula é o mais conservador de todos. Rio de Janeiro, Jornal do Brasil. Edição 117748. Disponível em: < http://ee.jornaldobrasil.com.br/reader/default.asp?ed=1356>. Acesso em: 29 jun. 2008.

PEREIRA, Luzete Adelaide. Educação, estado e revolução. 1985. 153 f. Tese (Doutorado em Educação) - Faculdade de Educação, Unicamp, Campinas, SP. 1985.

SAVIANI, Demerval. Educação socialista, pedagogia histórico-crítica e os desafios da sociedade de classes. In: LOMBARDI, J. C.; SAVIANI, D. (Org.) Marxismo e educação: debates contemporâneos. Campinas: Autores Associados, 2008. p. 223-274.

Os desafios da educação pública na sociedade de classes. In: ORSO, Paulino José (Org.). Educação, sociedade de classes e reformas universitárias. Campinas: Autores Associados, 2007. p. 9-26. 
. Desafios atuais da pedagogia histórico-crítica. In: SILVA JUNIOR, Celestino Alves. (Org.) Demerval Saviani e a educação brasileira. São Paulo: Cortez, 1994. p. 243-286.

. Pedagogia histórico-crítica. Primeiras aproximações. Campinas: Autores Associados, 2003. Educação e questões da atualidade. São Paulo: Cortez/ Livros do Tatu, 1991.

SILVA JÚNIOR, João dos Reis; FERRETTI, Celso João. $O$ institucional e a cultura da escola. São Paulo: Xamã, 2004.

TONET, Ivo. Educação contra o capital. Maceió: Edufal, 2007.

Educação, cidadania e emancipação humana. ljuí: Unijuí, 2005a.

Em defesa do futuro. Maceió: Edufal, 2005b.

TULLIO, Guaraciaba Aparecida. Afinal Proudhon venceu? Piracicaba: Unimep, 1989.

VIEIRA, Carlos Eduardo. O historicismo gramsciano e a pesquisa em educação. 1994. 248 f. Dissertação (Mestrado em Educação)- Faculdade de Educação, Pontifícia Universidade Católica de São Paulo, São Paulo, 1994.

Recebido em março de 2010

Aprovado em setembro de 2010

Carlos Henrique Ferreira Magalhães possui Doutorado em Educação pela UFSCar, mestrado em Educaçação e Licenciatura em Educação Física pela Universidade Federal do Rio de Janeiro. Atualmente é professor adjunto da Universidade Estadual de Maringá. E-mail: henryferrerlagmail.com.

João dos Reis Silva Júnior possui doutorado em Educação pela Pontifícia Universidade Católica de São Paulo e pós-doutoramento em Sociologia Política pela Unicamp. Atualmente desenvolve pósdoutoramento em Economia Política da Educação no Departamento de Economia da FEA-USP, com o trabalho "Economia política da universidade pública: um estudo de caso sobre política educacional dos governos FHC e Lula". É professor da Universidade Federal de São Carlos, bolsista de produtividade em pesquisa do CNPq. E-mail: joaodosreissilvajragmail.com. 


\section{Linhas Críticas}

A revista foi criada em 1995 com o objetivo de divulgar a produção científica de docentes e pesquisadores da Faculdade de Educação da Universidade de Brasília, como também editar artigos de autores de outros centros de investigação do Brasil e do exterior. Conta, desde o início, com um Comitê e Conselho Editorial qualificado, reconhecido nacional e internacionalmente.

Ao longo desses anos publicou 32 números com um total de 287 artigos escritos por 365 pesquisadores oriundos de 15 países: Alemanha, Argentina, Brasil, Canadá, Cuba, Espanha, Estados Unidos, França, Israel, Itália, México, Portugal, Rússia, Timor-Leste e Uruguai.

\section{NÚMEROS TEMÁTICOS}

No. 32 (vol. 17) Docência, formação e gestão

No. 31 (vol. 16) Hermenêutica, teoria crítica e educação

No. 30 (vol. 16) Educação profissional e tecnológica

No. 29 (vol. 15) Formação de profissionais da educação

No. 28 (vol. 15) Políticas educacionais e novas formas de regulação

No. 26 (vol. 14) Docência na educação superior

No. 24 (vol. 13) Educação e novas tecnologias

No. 22 (vol. 12) Educação, formação e aprendizagem

No. 21 (vol. 11) Edição comemorativa: 10 anos de Linhas Críticas

No. 20 (vol. 11) Políticas públicas para a educação

No. 18 (vol. 10) Gestão na educação

No. 17 (vol. 9) Novas tecnologias na educação

No. 16 (vol. 9) Educação especial

No. 15 (vol. 8) Criatividade na educação

No. 12 (vol. 7) Formação de professores e financiamento da educação

No. 7-8 ( vol. 4) Psicodrama na educação

No. 5-6 (vol. 3) Filosofia para crianças

No. 3-4 (vol. 2) Faculdade de Educação da UnB: um ideário pedagógico à altura do Brasil 